\title{
Impact of NILM-based energy efficiency on environmental degradation and kuznets hypothesis analysis
}

\author{
Keh-Kim Kee', Yun Seng Lim², Jianhui Wong², Kein-Huat Chua² \\ ${ }^{1}$ School of Engineering and Technology, University of Technology Sarawak, Sibu, Sarawak, Malaysia \\ ${ }^{2}$ Department of Electrical and Electronic Engineering, LKC Faculty of Engineering and Science, Universiti Tunku Abdul Rahman, \\ Kajang, Selangor, Malaysia
}

\begin{tabular}{l} 
Article Info \\
\hline Article history: \\
Received Jul 14, 2021 \\
Revised Dec 12, 2021 \\
Accepted Jan 5, 2022
\end{tabular}

Keywords:

$\mathrm{CO}_{2}$ emissions

Kuznets curve

Nonintrusive load monitoring

Predictive model

Scenario simulation

\begin{abstract}
Nonintrusive load monitoring (NILM) breaks down the aggregated electrical consumption data into individual appliances. The feedback of disaggregated data to the consumers enables awareness and behaviour change to conserve electricity, consequently reducing $\mathrm{CO}_{2}$ emissions to the environment. However, the limited literature regarding the impact of NILM and Kuznets hypothesis (EKC) analysis on $\mathrm{CO}_{2}$ emissions reduction has restricted policymakers in developing effective mitigation measures. This work aims to assess the impact of NILM-based based energy efficiency (EE) on environmental improvement. The combined approach of scenario simulation and EKC analysis was adopted to gauge the effectiveness of NILM that leads to sustainable development. The monotonically increase relationship between environmental degradation and economic growth in Malaysia without peaking beyond 2030 implies that the current mitigation measures and policies imposed may not effectively cope with the future power demands for sustainable development. NILM-based EE measures could be a great potential for reducing $\mathrm{CO}_{2}$ emissions by $10.2 \%$. The inverted-U curves and reduced turning points of environmental degradation from the income level of USD 20,063.36 to USD 16,305.19. Therefore, NILM approach can accelerate sustainable development with lower environmental deterioration. The work may beneficial to policymakers to analyse the impact and effectiveness of mitigation measures quantitatively.
\end{abstract}

This is an open access article under the CC BY-SA license.

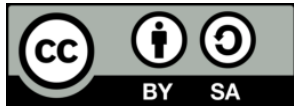

\section{Corresponding Author:}

Keh-Kim Kee

University of Technology Sarawak

Jalan Universiti, 96000 Sibu, Sarawak, Malaysia

Email: kkkee@ucts.edu.my

\section{INTRODUCTION}

Economic growth needs sustainable development with a balance between economic development and environmental conservation [1]. It is principally to maximize the benefits of economic development while minimizing or at least slowing down the environmental degradation without compromising the benefits of future generations. However, economic growth and environmental degradation could often be conflicting [2]. Since the 1980s, Malaysia has gained rapid industrialization with population growth. Therefore, the escalating electricity demand causes environmental degradation as the economy grows. As reported, the electricity consumption marked 13,152 ktoe in 2018, which is $4.33 \%$ higher than in 2017 [3]. Of which both residential $(21.2 \%)$ and commercial $(32.3 \%)$ sectors contribute $53 \%$ of electricity consumption in Malaysia [4] and $60 \%$ electricity in the world [4].

However, economic growth and resource consumption have caused $\mathrm{CO}_{2}$ emissions with environmental deterioration [5]. Sustainable development needs strategic planning of policies and measures 
to mitigate greenhouse gases (GHG) emissions. For instance, United Nations Framework Convention on Climate Change Conference (UNFCCC) has mandated the action taken by governments to reduce $\mathrm{CO}_{2}$ emissions for a sustainable and low-carbon society [6]. Furthermore, the fifth assessment report (AR5) of the intergovernmental panel on climate change (IPCC) affirmed that the acceleration of global warming due to $\mathrm{CO}_{2}$ emissions from anthropogenic activities [7].

As pledged to UNFCCC, Malaysia needs to reduce $45 \%$ GHG emissions in terms of carbon intensity by 2030 , relative to the 2005 level. Numerous mitigation policies have been implemented, including energy efficiencies (EE) and renewable energy (RE). Load monitoring approaches can obtain detailed electricity consumption data in the building sector. Nonintrusive load monitoring (NILM) is a cost-effective approach of detecting of the aggregated data from smart meters and inferring the disaggregated appliance consumption [8], [9]. Many use cases of NILM supporting the EE measures include the itemized and breakdown consumption information, demand-side management (DSM/DR) and peak load shaving, to name a few. The studies estimate that $20 \%$ of electricity consumption could be conserved [4], [10] NILM has opened up electricity conservation opportunities through consumers' awareness and behaviour change to shrink the release of $\mathrm{CO}_{2}$ emissions to the environment [11].

Various approaches forecast $\mathrm{CO}_{2}$ emissions from different contexts such as industrial sectors, provincial-level and national level, to assist policymakers in coping with the future environmental trend. Numerous predictive models, such as the IPAT model, STIRPAT model, and environmental kuznets curve (EKC) hypothesis, are studied to forecast environment degradation and environment-economic growth nexus [12]. As initiated by Crossman et al. [13], the EKC hypothesis is then revised by Roberts et al. [14] with an inverted U-curve relationship between $\mathrm{CO}_{2}$ emissions and economic development, as depicted in Figure 1 . There are three stages of economic development, i.e. (1) pre-industrial and (2) post-industrial, represented by developing countries and developed countries, and (3) industrial economies as the transition stage with a turning point [15].

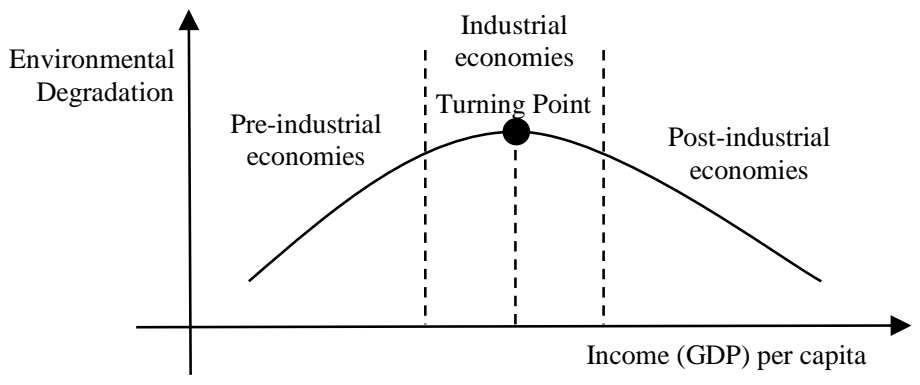

Figure 1. Inverted U-shaped curve of EKC hypothesis

EKC became a hot research topic among scholars [16]-[18], as policymakers potentially use the EKC curve and turning point as empirical evidence for sustainable development planning. In view of the current escalating trend of $\mathrm{CO}_{2}$ emissions without peaking and the pledge of COP21 for environmental protection, Malaysia has implemented numerous mitigation policies and measures. Therefore, it is crucial to assess the effectiveness of the mitigation measures of $\mathrm{CO}_{2}$ emissions reduction. However, the limited literature regarding the impact of NILM-based $\mathrm{EE}$ and $\mathrm{EKC}$ analysis on $\mathrm{CO}_{2}$ emissions reduction has restricted policymakers from developing strategic planning and effective measures. Few studies in the literature are confined only to the scope of using NILM-based EE measures to conserve electricity consumption [19]-[21], but without quantifying its impact on $\mathrm{CO}_{2}$ emissions.

To the best of our knowledge, the combined approach of scenario simulation and EKC hypothesis test to study the impact of the NILM-based EE measure on environment degradation is relatively unexplored among the researchers. The scenario simulation allows the adjustment of variables used for different "what if" scenarios to analyse and assess the target policy or measure. On the other hand, the EKC hypothesis is used to position the nation's economic development stage with a turning point for monitoring and evaluating the effectiveness of policies or measures. NILM-based EE is a potential measure for its impact on environmental degradation by reducing electricity consumption. In the following parts of this study, sections 2 and 3 discuss the methodology and analysis of results, respectively, followed by conclusions. 


\section{RESEARCH METHOD}

This work has proposed a combined scenario simulation and EKC hypothesis approach to quantify the impact of NILM-based EE measures on environmental improvement. The annual time series data of the identified predictor variables from technological innovations, demographic and socioeconomic are used to derive the statistical-based predictive models in this study. The regression models are used to forecast $\mathrm{CO}_{2}$ emissions. Secondly, scenario simulation is conducted to evaluate the impact of NILM on environmental degradation in 2019-2030 based on EKC analysis. The software used includes python and microsoft excel with data analysis. Figure 2 depicts the procedure in this work.

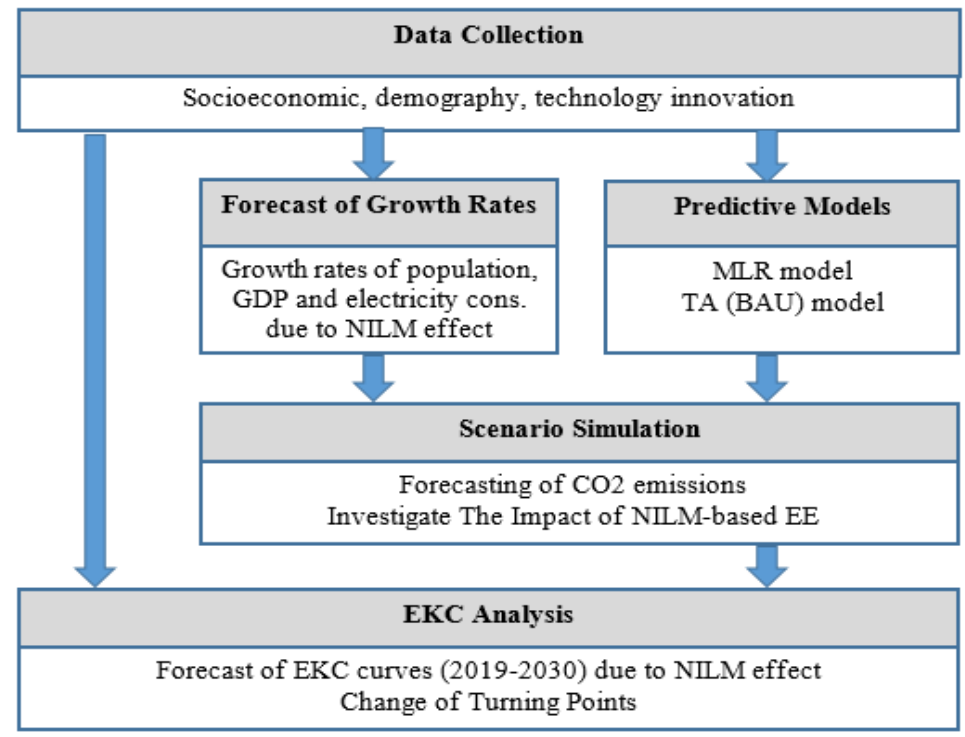

Figure 2. The procedure of the forecasting process

\subsection{Data collection}

In this work, annual time series data of 1996 to 2018 were adopted from world bank open data [22] and Malaysia energy commission [23]. The total $\mathrm{CO}_{2}$ and per-capita $\mathrm{CO}_{2}$ emissions are adopted as the responding variables. The identified predictors include electricity consumption (per-capita in $\mathrm{kWh}$ ), GDP, FDI net inflows, R\&D expenditure, Fossil generation and RE generation. The dataset is pre-processed with a normality test and stepwise regression modelling.

\subsection{Predictive models of $\mathrm{CO}_{2}$ emissions}

The regression-based predictive models of $\mathrm{CO}_{2}$ emissions are derived in this study with the identified predictors. Multiple linear regression (MLR) and trend analysis (TA) models have been developed and eventually validated to forecast $\mathrm{CO}_{2}$ emissions. A detailed description of the modelling procedure can be found in the authors' paper [24].

\subsection{Empirical study of EKC hypothesis in Malaysia}

EKC hypothesis is adopted to analyse the current status and forecast Malaysia's nexus relationship between economic development and environmental degradation. Consequently, it evaluates the effectiveness of mitigation policies and measures for strategic planning. Several works used a similar approach to evaluate renewable energy and tourism impact on environmental degradation [25], [26]. This study uses the forecasted $\mathrm{CO}_{2}$ emissions from the scenario simulation to quantify the impact of NILM-based EE measures in terms of emissions saving, EKC curve and the turning point for sustainable development. The nexus relationship is modelled by the modified-form model [27]. Therefore, the Malaysia EKC model can be re-written as:

$$
\text { CO2.PC }=B_{0}+B_{1} G D P . P C+B_{2} G D P . P C^{2}+B_{3} G D P . P C^{3}+\varepsilon_{i t}
$$

Where CO2.PC is $\mathrm{CO}_{2}$ emissions (per capita); GDP.PC is GDP (per capita); $B_{0}$ is constant; $B_{1} \sim B_{3}$ are the explanatory variables' coefficients; and $\varepsilon$ is the standard error term. The general model of (1) is used to test 
several forms of environment-economic development relationships include linear, quadratic and cubic functions, as listed in Table 1.

Table 1. Environment-economic development relationship for EKC hypothesis

\begin{tabular}{ccccl}
\hline & $\mathrm{B}_{1}$ & $\mathrm{~B}_{2}$ & $\mathrm{~B}_{3}$ & \multicolumn{1}{c}{ Relationship } \\
\hline 1 & 0 & 0 & 0 & Flat pattern or no relationship \\
2 & $>0$ & 0 & 0 & Monotonic increase relationship (linear) \\
3 & $<0$ & 0 & 0 & Monotonic decrease relationship (linear) \\
4 & $>0$ & $<0$ & 0 & Inverted-U-shaped relationship (quadratic) \\
& & & & The turning point TP of EKC is obtained as $-\mathrm{B}_{1} / 2 \mathrm{~B}_{2}$ \\
5 & $<0$ & $>0$ & 0 & U-shaped relationship (quadratic) \\
6 & $>0$ & $<0$ & $>0$ & N-shaped relationship (cubic) \\
7 & $<0$ & $>0$ & $<0$ & Opposite to the N-shaped (cubic) \\
\hline
\end{tabular}

\section{RESULTS AND DISCUSSION}

\subsection{Predictive modelling results}

Figure 3 shows the generated report of regression estimation results by graphical user interface (GUI) software written in Python. The predictors of both per-capita GDP and per-capita kWh show strong evidence against the null hypothesis (i.e. $H_{0}: B_{0}=B_{1}=B_{2}=B_{3}=0$ ) which have positive correlations with $\mathrm{CO}_{2}$ emissions. The coefficient of determination adjusted R2 is 0.959 signifies that the identified predictors could explain $95.9 \%$ variation in $\mathrm{CO}_{2}$ emissions. From the t-statistic result, p-values of 0.004 and 0.0000 for GDP.PC and kWh.PC predictors have confirmed their significance to the model. Furthermore, the model's goodness-of-fit is confirmed by the Prob (F-statistic) value of $4.85 \mathrm{e}-15(<0.05)$. The relationship is translated into MLR model (2) by using the regression coefficients.

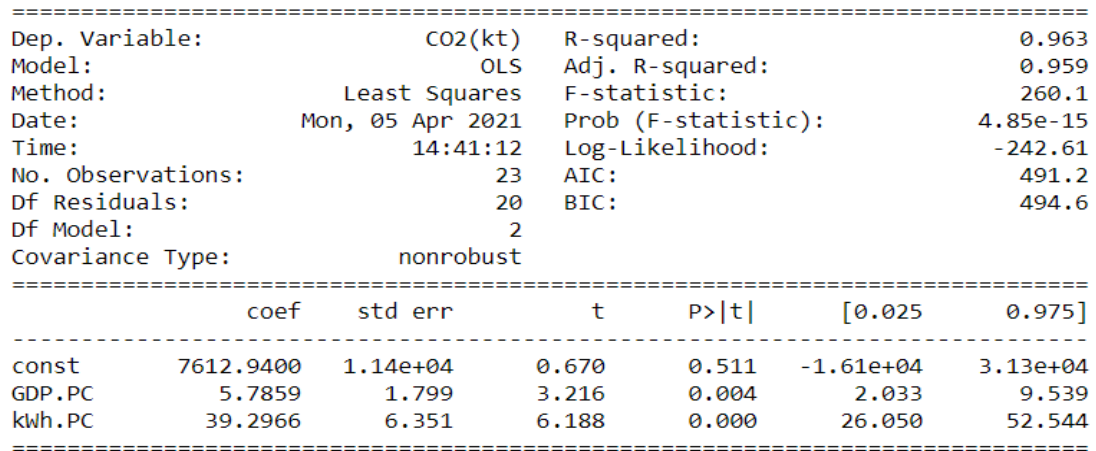

Figure 3. Generated results of regression estimation

$$
\operatorname{CO2}(k t)=7612.94+5.7859 \text { GDP.PC }+39.30 \mathrm{kWh} \cdot P C
$$

For the TA model, an adjusted R2 of 0.985 also signifies that the identified predictors could explain $98.5 \%$ variation in $\mathrm{CO}_{2}$ emissions. The t-test result has confirmed both year and year are significant to the model. The relationship is translated into a polynomial regression (3).

$$
\operatorname{CO2}(k t)=83449+10497 \text { Year }-133.93 \text { Year } 2
$$

\subsection{Scenario simulations}

To evaluate the impact of NILM-based EE, Malaysia's $\mathrm{CO}_{2}$ emissions of 2019-2030 are predicted by using (2) with the forecasted GDP and electricity consumption. Based on the relevant policies and research institutions, the variable growth rates are derived from world bank data, international monetary fund (IMF) report [28] and world energy markets observatory (WEMO) 2017 report [29]. Table 2 shows five scenario settings used in the scenario simulations. Scenario 1 serves as the baseline scenario or business-asusual (BAU), which employed the TA predictive model to forecast the $\mathrm{CO}_{2}$ emissions from 2019-2030 without considering any improvement in electricity conservation. On the other hand, scenarios 2-5 adopted the MLR model in section 3.1 to forecast $\mathrm{CO}_{2}$ emissions due to the NILM effect of reduced electricity consumption at different rates imposed, on top of the $4.8 \%$ base rate of annual growth increment. 
Table 2. Scenario settings of Malaysia

\begin{tabular}{|c|c|c|c|}
\hline \multirow{2}{*}{ Scenario } & \multicolumn{3}{|c|}{ The setting of growth rate } \\
\hline & Population & GDP & Electricity consumption \\
\hline 1. & \multicolumn{3}{|c|}{ The predicted $\mathrm{CO}_{2}$ emission by trend analysis (TA) or BAU scenario. } \\
\hline 2. & Use predicted data from World Bank Data. & $\begin{array}{l}\text { Use a } 4.8 \% \text { growth rate. } \\
\text { (Estimated rate by IMF) }\end{array}$ & $\begin{array}{l}\text { Baseline }(+4.8 \%) \text { with a reduction of } \\
2 \% \text { of electricity consumption }\end{array}$ \\
\hline 3. & & & Baseline with $5 \%$ reduction \\
\hline 4. & & & Baseline with $8 \%$ reduction \\
\hline 5. & & & Baseline with $12 \%$ reduction \\
\hline
\end{tabular}

By scenario simulation, the result highlights the significance of NILM-based EE on reducing $\mathrm{CO}_{2}$ emissions in Malaysia. A $12 \%$ electricity consumption reduction from NILM shrinks $10.2 \%$ (or $315852 \mathrm{kt}$ ) of $\mathrm{CO}_{2}$ emissions than the BAU model $(351739 \mathrm{kt}$ ). Therefore, NILM and its use cases can effectively improve environmental degradation and financial saving.

\subsection{NILM impact based on EKC analysis in Malaysia (1996-2030)}

To analyse the impact of NILM (reduced electricity consumption) and the long-run relationship between $\mathrm{CO}_{2}$ emissions and its economic growth (1996-2030), the EKC model test of the linear, quadratic and cubic functions used to fit with the coefficient of determination R2, t-statistic and F-statistic. The forecasted data of $\mathrm{CO}_{2}$ emissions is obtained from the scenario simulation in Section 3.2. The empirical results are shown in Table 3.

Table 3. Hypothesis tests of EKC model in Malaysia (1996-2030)

\begin{tabular}{|c|c|c|c|c|c|}
\hline Scenario & $\begin{array}{l}\text { Type of } \\
\text { function }\end{array}$ & $\begin{array}{c}\text { Expression of the function } \\
\text { (with p-values of T-test of predictors) }\end{array}$ & $\mathrm{R} 2$ & $\begin{array}{l}\text { Prob (F- } \\
\text { statistic) }\end{array}$ & Type of the curve \\
\hline \multirow[t]{3}{*}{$\begin{array}{l}\text { Scenario } 1 \\
\text { - BAU }\end{array}$} & Linear & $\begin{array}{l}\text { CO2.PC }=4.619+0.309 \text { GDP.PC } \\
(0.000)(0.000)\end{array}$ & 0.887 & $2.03 \mathrm{e}-17$ & $\begin{array}{l}\text { Monotonically } \\
\text { increasing }\end{array}$ \\
\hline & Quadratic & $\begin{array}{l}\text { CO2. PC }=3.716+0.507 \text { GDP. PC }-0.008 \text { GDP.PC } \\
(0.000)(0.000)(0.133)\end{array}$ & 0.915 & $9.76 \mathrm{e}-18$ & \\
\hline & Cubic & $\begin{array}{l}\text { CO2. PC }=1.808+1.268 \text { GDP.PC }- \\
0.093 \text { GDP.PC }+0.003 \text { GDP.PC }{ }^{3} \\
(0.104)(0.004)(0.050)(0.093)\end{array}$ & 0.914 & $3.45 \mathrm{e}-17$ & \\
\hline \multirow{3}{*}{$\begin{array}{l}\text { Scenario } 2 \\
-2 \% \text { red. } \\
\text { in } \mathrm{kWh}\end{array}$} & Linear & $\begin{array}{l}\text { CO2.PC }=4.562+0.309 \text { GDP.PC } \\
(0.000)(0.000)\end{array}$ & 0.887 & $2.03 \mathrm{e}-17$ & Inverted-U curve found. \\
\hline & Quadratic & $\begin{array}{l}\text { CO2.PC }=3.564+0.571 \text { GDP. PC }-0.014 \text { GDP. } P^{2} \\
(0.000)(0.000)(0.006)\end{array}$ & 0.908 & $9.76 \mathrm{e}-18$ & $\begin{aligned} & \text { Potential TP } \\
= & \text { USD } 20063.36\end{aligned}$ \\
\hline & Cubic & $\begin{array}{l}\text { CO2. PC }=1.808+1.268 \text { GDP. PC }- \\
0.093 \text { GDP.PC }+0.003 \text { GDP. PC } 3 \\
(0.104)(0.004)(0.050)(0.093)\end{array}$ & 0.914 & $8.85 \mathrm{e}-05$ & \\
\hline \multirow{3}{*}{$\begin{array}{l}\text { Scenario } 3 \\
-5 \% \text { red. } \\
\text { in } \mathrm{kWh}\end{array}$} & Linear & $\begin{array}{l}\text { CO2. } \mathrm{PC}=4.64+0.296 \text { GDP.PC } \\
(0.000)(0.000)\end{array}$ & 0.875 & $1.10 \mathrm{e}-16$ & Inverted- $\mathrm{U}$ curve found. \\
\hline & Quadratic & $\begin{array}{l}\text { CO2. PC }=3.548+0.582 \text { GDP.PC }-0.016 \text { GDP.PC } \\
(0.000)(0.000)(0.003)\end{array}$ & 0.902 & $2.60 \mathrm{e}-17$ & $\begin{aligned} & \text { Potential TP } \\
= & \text { USD } 18759.39\end{aligned}$ \\
\hline & Cubic & $\begin{array}{l}\text { CO2. PC }=1.555+1.372 \text { GDP.PC }- \\
0.105 \text { GDP.PC }+0.003 \text { GDP. } P^{3} \\
(0.151)(0.002)(0.026)(0.053)\end{array}$ & 0.911 & $5.63 e-17$ & \\
\hline \multirow{3}{*}{$\begin{array}{l}\text { Scenario } 4 \\
-8 \% \text { red. } \\
\text { in } \mathrm{kWh}\end{array}$} & Linear & $\begin{array}{l}\text { CO2. PC }=4.709+0.283 \text { GDP.PC } \\
(0.000)(0.000)\end{array}$ & 0.858 & $8.90 \mathrm{e}-16$ & Inverted-U curve found. \\
\hline & Quadratic & $\begin{array}{l}\text { CO2. PC }=3.531+0.592 \text { GDP. PC }-0.017 \text { GDP.PC } \\
(0.000)(0.000)(0.002)\end{array}$ & 0.893 & $1.07 \mathrm{e}-16$ & $\begin{aligned} & \text { Potential TP } \\
= & \text { USD } 17619.66\end{aligned}$ \\
\hline & Cubic & $\begin{array}{l}\text { CO2. PC }=1.295+1.479 \mathrm{GDP} . \mathrm{PC}- \\
0.117 \mathrm{GDP} . \mathrm{PC}^{2}+0.003 \mathrm{GDP} . \mathrm{PC}^{3} \\
(0.226)(0.001)(0.130)(0.030)\end{array}$ & 0.906 & $1.35 \mathrm{e}-16$ & \\
\hline \multirow{3}{*}{$\begin{array}{l}\text { Scenario } 5 \\
-12 \% \text { red. } \\
\text { in } \mathrm{kWh}\end{array}$} & Linear & $\begin{array}{l}\text { CO2. PC }=4.813+0.264 \text { GDP.PC } \\
(0.000)(0.000)\end{array}$ & 0.827 & $2.51 \mathrm{e}-14$ & Inverted-U curve found. \\
\hline & Quadratic & $\begin{array}{l}\text { CO2. PC }=3.507+0.607 \text { GDP. PC }-0.019 \text { GDP. } P^{2} \\
(0.000)(0.000)(0.001)\end{array}$ & 0.875 & $1.40 \mathrm{e}-15$ & $\begin{aligned} & \text { Potential TP } \\
= & \text { USD } 16305.19\end{aligned}$ \\
\hline & Cubic & $\begin{array}{l}\text { CO2. PC }=0.934+1.628 \text { GDP.PC }- \\
0.134 \mathrm{GDP} . \mathrm{PC}^{2}+0.004 \mathrm{GDP} . \mathrm{PC}^{3} \\
(0.384)(0.000)(0.005)(0.14)\end{array}$ & 0.894 & $8.47 \mathrm{e}-16$ & \\
\hline
\end{tabular}

Based on Table 3, the EKC curve functions for different scenarios sets are identified. Figure 4 depicts the NILM impact on environmental degradation in Malaysia (1996-2030) from the perspective of the 
EKC hypothesis. Scenario 1 (BAU setting) has been tested with different functions, i.e. linear, quadratic, and cubic. It is empirically identified BAU scenario has a monotonically increase relationship. Neither inverted-U curve nor turning point found with an increasing trend of $\mathrm{CO}_{2}$ emissions without peaking. The phenomenon can be explained that Malaysia's current mitigation measures and policies may not effectively cope with the future demand for sustainable development. Hence, the policymakers should devise strategic planning of environmental improvement as earlier as possible.

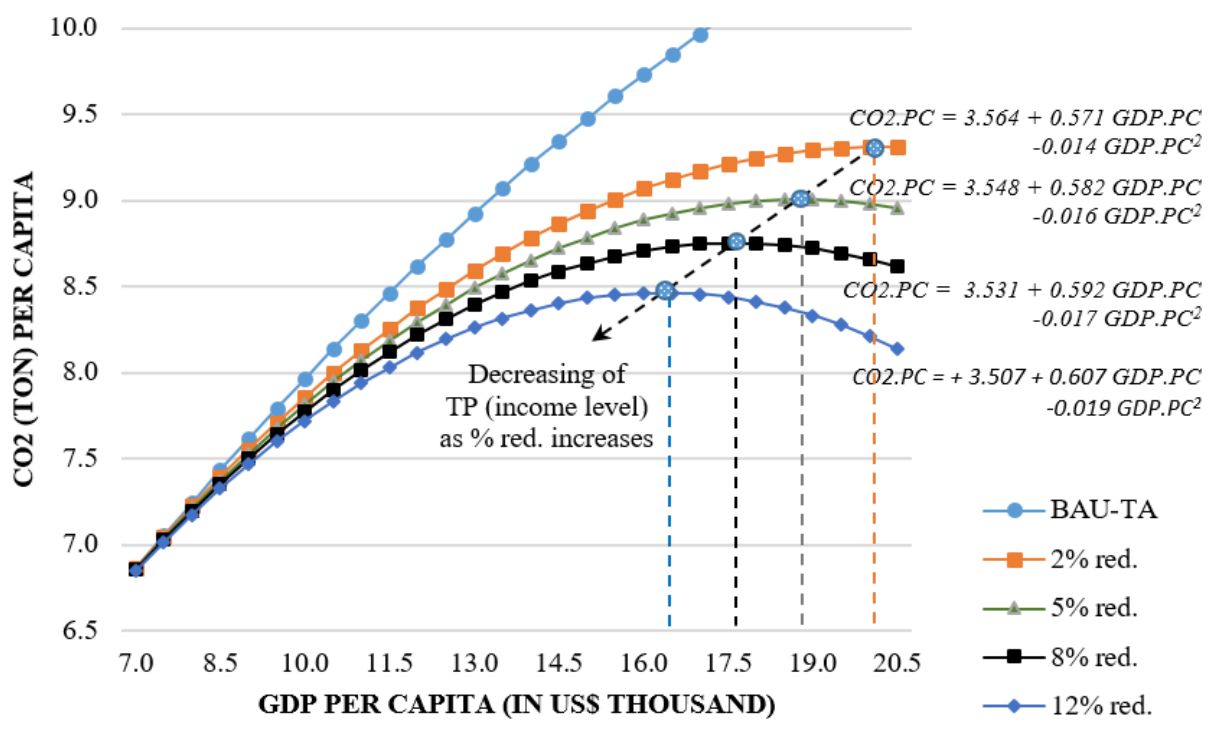

Figure 4. Impact of NILM from the perspective of EKC hypothesis

As one of the potential approaches to mitigate environmental degradation, it is crucial to quantitatively assess the impact of NILM-based EE measures by conducting the scenario simulation and the hypothesis test on the EKC model. As shown in Figure 4, Scenario 2 of NILM-based EE with a $2 \%$ reduction of electricity consumption imposed, inverted-U curve and turning point are found as empirical evidence of EKC. The turning point is identified as USD 20,063.36 and implies that there would be environmental improvement once the GDP per-cap level is improved. The evaluation continued with Scenario 3-5 by gradually increasing the reduction rate of electricity consumption and the EKC hypothesis test conducted. All the scenarios with NILM-based EE found compliance to the EKC model's inverted-U curve. The turning point is significantly reduced to USD $16,305.19$ at a $12 \%$ reduction in electricity consumption. The empirical result is well-supported by several works [30], [31] that the developing countries could attain higher levels of economic growth at a lower environmental cost by "tunnelling" through the EKC curve with a better sustainable development path [32].

\section{CONCLUSION}

Strategic planning of policies and environmental measures is vital to the policymakers for sustainable development. The quantitative analysis of the impact of NILM-based EE measure with the EKC hypothesis is presented. It is the first attempt to quantitatively analyse its impact on environmental degradation from the EKC hypothesis perspective. The significance of this work is as; i) the NILM-based measure could reduce $\mathrm{CO}_{2}$ emissions by $10.2 \%$ compared with the BAU model, ii) the BAU scenario simulation of Malaysia 2019-2030 found a monotonically increase relationship between environmental degradation and economic growth. It implies that the current mitigation measures and policies imposed may not be effective enough to cope with the future power demands for sustainable development. Hence, the policymakers should restructure the strategic planning of environmental improvement as earlier as possible, iii) the inverted- $U$ curves show that the turning points of environmental degradation have been reduced from the income level from USD 20,063.36 to USD 16,305.19 with the increment of reduction rates in electricity consumption. It implied NILM-based EE measures could accelerate sustainable development with lower 
environmental deterioration, iv) the shift or decreasing trend of turning point levels of GDP income implies that an effective policy can "tunnel through" the EKC curve with lower environmental deterioration.

Consequently, these results may help policymakers devise and evaluate the strategic planning of policies and measures that ensures a balance between economic growth and environmental degradation. Other measures such as renewable energy, taxes, and policies can be further studied in the proposed analytical framework for future improvement.

\section{ACKNOWLEDGEMENTS}

This work is fully funded by the UTS Research Grant (Project ID: UCTS/RESEARCH/4/2019/17) of the University of Technology Sarawak. The authors would like to thank the Centre of Research and Development (CRD) of UTS for its support.

\section{REFERENCES}

[1] M. Todaro and S. C. Smith, "Economic Development Eleventh Edition," 2006.

[2] A. Khan, Y. Chenggang, S. Bano, and J. Hussain, "The empirical relationship between environmental degradation, economic growth, and social well-being in Belt and Road Initiative countries," Environmental Science and Pollution Research, vol. 27, no. 24, pp. 30800-30814, 2020.

[3] S. Tenaga, "Malaysia energy statistics handbook 2018," Suruhanjaya Tenaga (Energy Comm), 2019

[4] S. Tenaga, "National Energy Balance 2013," Energy Comm. ISSN0128-6323, 2014.

[5] J. V. D. Akker, "United Nation Development Programme (UNDP). Achieving industrial energy efficiency in Malaysia," International consultant, ASCENDIS, 2006.

[6] United Nations, "Adoption Of The Paris Agreement-Conference of the Parties COP 21," Adoption Paris Agreement Proposal by President, 2015, pp. 1-32.

[7] E. Edenhofer, "AR5 Climate Change 2014: Mitigation of Climate Change-IPCC," Working Group III Contribution to the Fifth Assessment Report of the Intergovernmental Panel on Climate Change, 2014. [Online]. Available: https://www.ipcc.ch/site/assets/uploads/2018/02/ipcc_wg3_ar5_full.pdf.

[8] M. Gaur and A. Majumdar, "Disaggregating transform learning for non-intrusive load monitoring," IEEE Access, vol. 1, no. 1, pp. 1-99, 2018, doi: 10.1109/ACCESS.2018.2850707.

[9] K. -K. Kee, Y. S. Lim, J. Wong and K. H. Chua, "Non-Intrusive Load Monitoring (NILM) - A Recent Review with Cloud Computing," IEEE International Conference on Smart Instrumentation, Measurement and Application (ICSIMA), 2019, pp. 1-6, doi: 10.1109/ICSIMA47653.2019.9057316.

[10] K. C. Armel, A. Gupta, G. Shrimali, and A. Albert, "Is disaggregation the holy grail of energy efficiency? The case of electricity," Energy Policy, vol. 52, pp. 213-234, 2013, doi: 10.1016/j.enpol.2012.08.062.

[11] T. Babaei, H. Abdi, C. P. Lim, and S. Nahavandi, "A study and a directory of energy consumption data sets of buildings," Energy and Buildings, vol. 94, pp. 91-99, 2015, doi: 10.1016/j.enbuild.2015.02.043.

[12] X. Li, Y. Song, Z. Yao, and R. Xiao, "Forecasting China's CO2 Emissions for Energy Consumption Based on Cointegration Approach," Discrete Dynamics in Nature and Society, vol. 2018, ID. 4235076, pp. 1-10, 2015-8, doi: 10.1155/2018/4235076.

[13] G. Grossman and A. Krueger, "Environmental Impacts of a North American Free Trade Agreement," National Bureau of Economic Research, 1991.

[14] J. T. Roberts and P. E. Grimes, "Carbon intensity and economic development 1962-91: A brief exploration of the environmental kuznets curve," World Development, vol. 25, no. 2, pp. 191-198, 1997, doi: 10.1016/S0305-750X(96)00104-0.

[15] R. Ginevicius, G. Lapinskienè, and K. Peleckis, "The evolution of the environmental Kuznets curve concept: The review of the research," Panoeconomicus, vol. 64, no. 1, pp. 93-112, 2017, doi: 10.2298/PAN150423012G.

[16] A. R. Gill, K. K. Viswanathan, and S. Hassan, "The Environmental Kuznets Curve (EKC) and the environmental problem of the day," Renewable and Sustainable Energy Reviews,vol. 81, Part. 2, pp. 1636-1642, 2018, doi: 10.1016/j.rser.2017.05.247.

[17] E. Akbostanci, S. T. Aşik, and G. I. Tunç, "The relationship between income and environment in Turkey: Is there an environmental Kuznets curve?," Energy Policy, vol. 37, no. 3, pp. 861-867, 2009, doi: 10.1016/j.enpol.2008.09.088.

[18] M. Galeotti, M. Manera, and A. Lanza, "On the robustness of robustness checks of the environmental kuznets curve hypothesis," Environmental and Resource Economics, vol. 45, no. 551, 2009.

[19] S. Biansoongnern and B. Plungklang, "Non-Intrusive Appliances Load Monitoring (NILM) for Energy Conservation in Household with Low Sampling Rate,” Procedia Computer Science, vol. 86, pp. 172-175, 2016, doi: 10.1016/j.procs.2016.05.049.

[20] F. D. Garcia, W. A. Souza, I. S. Diniz, and F. P. Marafão, "NILM-based approach for energy efficiency assessment of household appliances," Energy Informatics, vol. 3, no. 10, pp. pp. 1-21, 2020, doi: 10.1186/s42162-020-00131-7.

[21] A. Ruano, A. Hernandez, J. Ureña, M. Ruano, and J. Garcia, "NILM Techniques for Intelligent Home Energy Management and Ambient Assisted Living: A Review," Energies, vol. 12, no. 2203, pp. 1-29, 2019, doi: 10.3390/en12112203.

[22] The World Bank, "World Development Indicators World Bank Data Bank." [Online]. Available: https://databank.worldbank.org/source/world-development-indicators. [Accessed: 10-Mar-2021]

[23] Suruhanjaya Tenaga Energy Commision, "Statistics - Malaysia Energy Information Hub." [Online]. Available: https://meih.st.gov.my/statistics;jsessionid=DD030E510A578E9B4E2F8797E81C410E?p_auth=XLWco4Qr\&p_p_id=Eng_Statis tic_WAR_STOASPublicPortlet\&p_p_lifecycle $=1 \& p \_p \_s t a t e=\operatorname{maximized\& p\_ p\_ mode=}=$ view\&p_p_col_id=column-

$1 \&$ p_p_col_pos=1\&p_p_col_count=2\&_Eng_Statistic_WAR_STOASPublicPortlet_execution=e1s1\&_Eng_Statistic_WAR_STO ASPublicPortlet_eventId=ViewStatistic3\&categoryId=4\&flowId=7. [Accessed: 04-Jan-2022]

[24] K.-K. Kee, Y. S. Lim, J. Wong, and K. H. Chua, "Impact of Nonintrusive Load Monitoring on CO2 Emissions in Malaysia," Bulletin of Electrical Engineering and Informatics, vol. 10, no. 4, pp. 1803-1810, 2021, doi: 10.11591/eei.v10i4.2979.

[25] C. Ișik et al., "An Evaluation of the Tourism-Induced Environmental Kuznets Curve (T-EKC) Hypothesis: Evidence from G7 Countries," Sustainability, 2020, vol. 12, no. 21, pp. 1-11, 2020, doi: 10.3390/su12219150.

[26] A. R. Gill, K. K. Viswanathan, and S. Hassan, "A test of environmental Kuznets curve (EKC) for carbon emission and potential of renewable energy to reduce green house gases (GHG) in Malaysia," Environment, Development and Sustainability, vol. 20, no. 3 , pp. 1103-1114, 2018. 
[27] S. Dinda, "Environmental Kuznets Curve Hypothesis: A Survey," Ecological Economics, vol. 49, no. 4, pp. 431-455, 2004, doi: 10.1016/j.ecolecon.2004.02.011.

[28] Statista, "Malaysia - Gross domestic product (GDP) growth rate 2026" [Online]. Available: https://www.statista.com/statistics/318977/gross-domestic-product-gdp-growth-rate-in-malaysia/. [Accessed: 04-Jan-2022].

[29] Capgemini, "World Energy Markets Observatory (WEMO) for 2017" [Online]. Available: https://www.capgemini.com/wpcontent/uploads/2017/11/wemo2017-vst27-web.pdf. [Accessed: 04-Jan-2022].

[30] M. Munasinghe, "Is environmental degradation an inevitable consequence of economic growth: tunneling through the environmental Kuznets curve,” Ecological Economics, vol. 29, no. 1, pp. 89-109, 1999, doi: 10.1016/S0921-8009(98)00062-7.

[31] E. Choi, A. Heshmati, and Y. Cho, "An Empirical Study of the Relationships between CO2 Emissions, Economic Growth and Openness," IZA Discussion, no. 5304, pp. 1-29, 2010

[32] R. Čiegis, D. Štreimikiene, and E. K. Zavadskas, "The use of the environmental Kuznets curve: Environmental and economic implications," International Journal of Environment and Pollution, vol. 33, no. 2-3, pp. 313-335, 2008.

\section{BIOGRAPHIES OF AUTHORS}
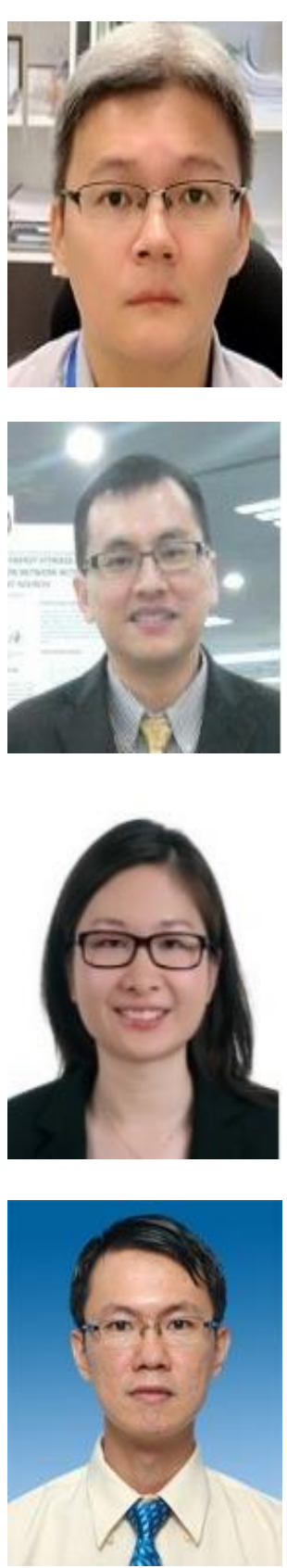

Keh-Kim Hee (D) 8d SC P is a Senior Lecturer of University College of Technology Sarawak (UCTS) and Chartered Engineer registered with Engineering Council of UK (ECUK). Kee is also a senior member of Institute of Electrical \& Electronic Engineers (SMIEEE). His current research interests are AI/ML-based solutions with hardware and software design, energy efficiency solutions with data analytics and load monitoring by smart metering, and cloud computing. He can be contacted at email: kkkee@uts.edu.my.

Yun Seng Lim (iD $8 \mathrm{SC}$ P received B.Eng (Hons) and $\mathrm{PhD}$ from University of Manchester Institute of Science and Technology (UMIST), United Kingdom, in 1998 and 2001 respectively. He is currently a professor of Universiti Tunku Abdul Rahman (UTAR). He is a senior member of IEEE and the Fellow of ASEAN Academy of Engineering and Technology (AAET). As the recipient of the Top Research Scientist Malaysia in 2018, Dr. Lim is also a lead author for the working group III of Intergovernmental Panel on Climate Change (IPCC). He can be contacted at email: yslim@utar.edu.my.

Jianhui Wong (iD SIS SC P received her B.Eng. (Hons) Electrical and Electronic Engineering, MSc. Eng. and Ph.D. Eng. (Electrical) from Universiti Tunku Abdul Rahman (UTAR). She is an Assistant Professor of UTAR, professional engineer registered with the Board of Engineer Malaysia (BEM) and corporate member of the Institute of Engineers Malaysia (IEM). She has actively involved as the principle and co-researcher in the research projects receiving a total amount of RM3 million research grants from various agencies. Her research interests including power system study, energy management and smart grid. She can be contacted at email: wongjh@utar.edu.my.

Kein Huat Chua (D) 81 SC P (b. 1979) received the B. Eng. degree in electrical, electronics and system engineering from Universiti Kebangsaan Malaysia, Selangor, Malaysia, in 2004. He received his M. Eng. degree in electrical energy and power system from Universiti Malaya, Kuala Lumpur, Malaysia, in 2008. He received his $\mathrm{PhD}$ in Electrical Engineering from Universiti Tunku Abdul Rahman, Kuala Lumpur, Malaysia. He is currently an Assistant Professor at Universiti Tunku Abdul Rahman. He can be contacted at email: chuakh@utar.edu.my. 